\title{
Symptoms associated with an abnormal echocardiogram in elderly primary care hypertension patients
}

\author{
L. Ringoir • J. W. Widdershoven • S. S. Pedersen • \\ J. M. Keyzer • V. J. Pop
}

Published online: 4 April 2014

(C) The Author(s) 2014. This article is published with open access at Springerlink.com

\begin{abstract}
Background The prevalence and diagnostic value of heart failure symptoms in elderly primary care patients with hypertension is unknown.

Aim To assess the prevalence, sensitivity, specificity, positive and negative predictive value of symptoms in association with an abnormal echocardiogram.

Design and setting Cross-sectional screening study in five general practices in the south-east of the Netherlands.

Method Between June 2010 and January 2013, 591 primary care hypertension patients aged between 60 and 85 years were included, without known heart failure and not treated by a cardiologist. All patients underwent an echocardiogram and a structured interview including assessment of heart failure
\end{abstract}

L. Ringoir · J. W. Widdershoven $\cdot$ S. S. Pedersen $\cdot$ J. M. Keyzer $\cdot$

V. J. Pop $(\bowtie)$

Department of Medical and Clinical Psychology, Center of Research on Psychology in Somatic Diseases (CoRPS), Tilburg University, PO Box: 90153, 5000 LE Tilburg, the Netherlands

e-mail: V.J.M.Pop@tilburguniversity.edu

J. W. Widdershoven

Department of Cardiology, TweeSteden Hospital, Dr. Deelenlaan 5, 5042 AD Tilburg, the Netherlands

\section{S. S. Pedersen}

Department of Cardiology, Thoraxcenter, Erasmus Medical Center, Rotterdam, the Netherlands

\section{S. S. Pedersen}

Department of Cardiology, Odense University Hospital,

Odense, Denmark

\section{S. S. Pedersen}

Institute of Psychology, University of Southern Denmark,

Odense, Denmark

L. Ringoir $\cdot$ J. M. Keyzer

PoZoB, Veldhoven, the Netherlands symptoms: shortness of breath, fatigue, oedema, cold extremities, and restless sleep.

Results and conclusion Restless sleep was reported by $25 \%$, cold extremities by $23 \%$, fatigue by $19 \%$, shortness of breath by $17 \%$, and oedema by $13 \%$. Oedema was the only symptom significantly associated with an abnormal echocardiogram (positive predictive value was $45 \%$, sensitivity $20 \%$, and specificity $90 \%$, OR 2.12; $95 \% \mathrm{CI}=1.23-3.64$ ), apart from higher age (OR 1.06; $95 \% \mathrm{CI}=1.03-1.09)$, previous myocardial infarction (OR 3.00; $95 \% \mathrm{CI}=1.28-7.03$ ), and a systolic blood pressure of $>160 \mathrm{mmHg}(\mathrm{OR} 1.62 ; 95 \% \mathrm{CI}=$ $1.08-2.41)$. Screening with echocardiography might be considered in patients with oedema.

Keywords Primary health care $\cdot$ Hypertension $\cdot$ Heartfailure Echocardiography

\section{Introduction}

Hypertension is highly prevalent, with the Framingham study showing a lifetime risk for developing hypertension of $90 \%$ in people with a normal blood pressure at age 55 [1]. A high blood pressure can result in coronary artery disease and changes in ventricular function and structure [2], and is a major risk factor for incident heart failure [3], with a 5-year survival rate of $35 \%$ according to previous research [4]. Early diagnosis and treatment of heart failure are crucial for reducing heart failure related morbidity and mortality [5-7]. General practitioners (GPs) are most frequently involved in the diagnosis of heart failure [8]. More severe hypertension in primary care patients is associated with a higher risk of cardiovascular events [9], and lowering blood pressure can reduce risk of major cardiovascular events [10]. However, less than $50 \%$ of patients above the age of 65 are properly managed [11-13]. Therefore, elderly hypertension patients, 
especially those with less than optimal blood pressure, are at high risk for heart failure.

Several important patient-reported symptoms of heart failure are oedema, dyspnoea, and fatigue [14-16]. Because most patients with possible heart failure will present first in primary care [16], it is important for a GP or practice nurse (PN) to identify symptoms predictive of this condition. However, most studies on symptoms used for assessment of heart failure have focused on hospital populations [8] and/or on patients who presented with dyspnoea $[17,18]$, or had suspected heart failure [19]. Furthermore, the majority of studies evaluated symptoms only in association with left ventricular systolic dysfunction and did not take other relevant abnormalities such as diastolic function into account $[5,8]$. Left ventricular hypertrophy (LVH), an enlarged left atrium, valvular heart disease, and wall motion abnormalities can also be major causes of heart failure and are related to coronary artery disease [20-22].

Echocardiography is seen as the gold standard for the diagnosis or confirmation of cardiac dysfunction associated with heart failure [5] and can be used to detect cardiac abnormalities [2]. Although the diagnostic value of symptoms and signs of heart failure has been the topic of debate [17], attention to symptoms can still be of relevance in patients at risk for heart failure [5].

Until now it is unclear in elderly primary care patients with hypertension which heart failure symptoms may be associated with an abnormal echocardiogram. The objectives of the current study were to examine (1) the prevalence of symptoms which are in general related to cardiac dysfunction reflected by an abnormal echocardiogram, (2) the sensitivity, specificity, positive, and negative predictive value of symptoms of an abnormal echocardiogram, and (3) the relation between the symptoms and an abnormal echocardiogram, after adjustment for several confounders.

\section{Methods}

Study design and patient population

Between June 2010 and January 2013, primary care patients aged between 60 and 85 years, with an International Classification of Primary Care for hypertension (K86 or K87) as captured from their medical record, were recruited from five general practices affiliated with the primary care organisation $\mathrm{PoZoB}$ (a primary care organisation of approximately $200 \mathrm{GPs}$, located in the south of the Netherlands) for this cross-sectional study. Exclusion criteria were: previous diagnosis of heart failure, current treatment by a cardiologist, history of severe psychiatric illness other than mood/anxiety disorders and/or cognitive impairments (e.g. dementia), terminal cancer, and insufficient knowledge of the Dutch language. This study was approved by the medical ethics committee of the Elisabeth Hospital in Tilburg, the Netherlands.

Study procedure and data collection

Eligible patients received written information about the study by mail and were asked to sign an informed consent form. Patients were contacted by phone, and in case of informed consent an appointment for an interview at their local GP office was scheduled. This interview consisted of a structured interview of $1 \mathrm{~h}$ by a trained nurse. At the end of the intake, an appointment for the echocardiogram was scheduled which also took place at the local GP office.

Measurements

\section{Demographic and clinical variables}

Information on demographic and clinical variables was obtained from purpose-designed questions in the interview and included gender, age, marital status, and educational level. Furthermore, blood pressure was measured twice and the average blood pressure was used to dichotomise systolic blood pressure ( $>160 \mathrm{mmHg}$ was cut-off). Height and weight were measured in order to calculate the body mass index (BMI). Information on clinical variables retrieved from the patients' medical records included myocardial infarction (MI) and peripheral arterial disease.

\section{Assessment of symptoms}

Information on heart failure symptoms was obtained during the interview. Structured and standardised questions were used to assess heart failure symptoms. Symptoms were dichotomised (yes/no) and defined as: shortness of breath during moderate exertion (e.g. walking), regularly occurring fatigue, oedema of the legs, ankles and/or feet, having cold extremities, and restless sleep, during the past 4 weeks.

\section{Assessment of the echocardiogram}

The echocardiogram was performed and evaluated by an experienced echocardiographer of the local primary care laboratory located in Eindhoven, the Netherlands. All the echocardiograms were reviewed by a cardiologist specialised in echocardiography, who indicated if the echocardiogram was abnormal according to a protocol suitable for primary care, based on current guidelines [23, 24]. The definition of an abnormal echocardiogram is shown in Table 1. 
Table 1 Prevalence of abnormal echocardiogram parameters in 591 elderly primary care hypertension patients

\begin{tabular}{ll}
\hline & $\begin{array}{l}\text { Total } \\
(n=591)\end{array}$ \\
\hline $\begin{array}{l}\text { Abnormalities on the echocardiogram } \\
\text { LAVI }>29 \mathrm{ml} / \mathrm{m}^{2}\end{array}$ & $60(10 \%)$ \\
LVEF $<55 \%$ & $51(9 \%)$ \\
Valvular abnormalities & $48(8 \%)$ \\
LVH septal and posterior wall thickness of $\geq 13$ & $36(6 \%)$ \\
$\quad$ mm (moderate or severe) & $35(6 \%)$ \\
$\begin{array}{l}\text { Diastolic dysfunction (E/A ratio of }<1 \text { and DTs } \\
\text { of }>200 \text { ms, and presence of LVH in case of } \\
\text { grade I diastolic dysfunction) }\end{array}$ & \\
$\quad \begin{array}{l}\text { Wall motion abnormalities (hypokinesia, akinesia } \\
\text { and dyskinesia) }\end{array}$ & $26(4 \%)$ \\
RVH; subcostal wall thickness of $\geq 6$ mm (mild, \\
$\quad$ moderate or severe) \\
Total $\geq 1$ abnormality \\
$\quad$ Total $\geq 2$ abnormality & $15(3 \%)$ \\
\hline
\end{tabular}

$L A V I$ left atrial volume index, $L V E F$ left ventricular ejection fraction, $L V H$ left ventricular hypertrophy, $R V H$ right ventricular hypertrophy, $D T$ deceleration time

\section{Statistical analyses}

Statistical analyses were performed using the IBM Statistical Package for the Social Sciences version 18.0. Differences in baseline characteristics were compared between normal and abnormal echocardiograms and assessed with Chi-square tests or Student's/Welch's T-tests when appropriate. For each symptom and clinical variable, the sensitivity, specificity, positive predictive value, and negative predictive value with $95 \%$ confidence intervals were calculated.

Adjusted odds ratios were calculated using multiple logistic regression, with an abnormal echocardiogram (taking all cardiac abnormalities together) as dependent variable. A possible relation between symptoms and an abnormal echocardiogram were adjusted for age, gender, education, having a partner, previous MI, peripheral arterial disease, and elevated systolic blood pressure of $>160 \mathrm{mmHg}$.

\section{Results}

Patient recruitment

From 6 different GP practices, 913 eligible patients with hypertension were approached and $619(68 \%)$ patients agreed to participate. Of these participants, 2 were excluded post-hoc because they met the exclusion criterion of being treated by a cardiologist, 5 were excluded post-hoc because the echocardiogram was not of sufficient quality and 16 patients did not have an echocardiogram, of which 3 were admitted to the hospital, 1 died, and 12 did not show up. Patients with congenital disease and/or hypertrophic cardiomyopathy were excluded from analyses $(n=5)$, leaving a total of $591(65 \%)$ patients for analysis.

\section{Baseline characteristics}

Tables 2 shows the baseline characteristics. The mean age of the study patients was $70 \pm 6.5$ years and $44 \%$ were male $(n=$ 262). Patients with an abnormal echocardiogram were significantly older, less often had a partner, were more likely to have had a previous MI, and had a higher systolic blood pressure as compared with the patients with a normal echocardiogram. Abnormalities on the echocardiogram were present in $30 \%$ of the study sample (Table 1).

Heart failure symptoms and abnormal echocardiogram

Restless sleep was the most prevalent symptom ( $25 \%, n=$ 149). The most sensitive was shortness of breath with a sensitivity of $32 \%$. The most specific symptom was oedema of the ankles, feet, or legs, with a high specificity of $90 \%$. Oedema also had the highest positive predictive value (45\%) and negative predictive value (73\%) for an abnormal echocardiogram (Table 3).

In adjusted analysis (Table 4), oedema was significantly and independently related to an abnormal echocardiogram adjusted for age, sex, having a partner, the co-existence of type 2 diabetes or peripheral arterial disease, systolic blood pressure $>160 \mathrm{mmHg}$. The other symptoms were not significantly associated with an abnormal echocardiogram in adjusted analysis.

\section{Discussion}

The current study shows that regular restless sleep was reported by $25 \%$, having cold extremities by $23 \%$, fatigue by $19 \%$, shortness of breath by $17 \%$, and oedema of legs, ankles and/ or feet by $13 \%$. An abnormal echocardiogram was present in $30 \%$. Oedema is an important symptom of cardiac dysfunction as reflected by an abnormal echocardiogram. In adjusted analysis, oedema was the only symptom that was significantly associated with abnormal echocardiogram apart from higher age, previous MI, and a systolic blood pressure of $>160 \mathrm{mmHg}$. The symptoms shortness of breath, fatigue, having cold extremities, and having restless sleep were of limited value in predicting an abnormal echocardiogram.

Strengths and limitations

This study is among the first to evaluate the value of heart failure symptoms in the diagnosis of cardiac dysfunction in 
Table 2 Baseline characteristics of 591 elderly primary care hypertension patients

\begin{tabular}{|c|c|c|c|c|}
\hline Characteristic & Total, $N=591$ & $\begin{array}{l}\text { Normal } \\
\text { echocardiogram, } N=416\end{array}$ & $\begin{array}{l}\text { Abnormal } \\
\text { echocardiogram, } N=175\end{array}$ & $P$-value \\
\hline \multicolumn{5}{|l|}{ Demographics } \\
\hline Male & $262(44 \%)$ & $180(43 \%)$ & $82(47 \%)$ & 0.423 \\
\hline Female & $329(56 \%)$ & $236(57 \%)$ & $93(53 \%)$ & 0.423 \\
\hline Age, mean (SD) & $69.9(6.5)$ & $69.1(6.1)$ & $72.0(7.0)$ & $<0.001$ \\
\hline Low education & $76(13 \%)$ & $55(13 \%)$ & $21(12 \%)$ & 0.686 \\
\hline Having a partner & $443(75 \%)$ & $324(78 \%)$ & $119(68 \%)$ & 0.011 \\
\hline \multicolumn{5}{|l|}{ Lifestyle } \\
\hline Current smoker & $77(13 \%)$ & $61(15 \%)$ & $16(9 \%)$ & 0.069 \\
\hline Regular alcohol use ( $\geq 2$ glasses per day) & $188(32 \%)$ & $133(32 \%)$ & $55(31 \%)$ & 0.897 \\
\hline \multicolumn{5}{|l|}{ Clinical characteristics and risk factors } \\
\hline Previous myocardial infarction & $27(5 \%)$ & $11(3 \%)$ & $16(9 \%)$ & 0.001 \\
\hline Peripheral artery disease & $23(4 \%)$ & $12(3 \%)$ & $11(6 \%)$ & 0.051 \\
\hline TIA/stroke & $52(9 \%)$ & $33(8 \%)$ & $19(11 \%)$ & 0.252 \\
\hline Diabetes type 2 & $67(11 \%)$ & $45(11 \%)$ & $22(13 \%)$ & 0.539 \\
\hline GFR $<60(n=575)$ & $102(18 \%)$ & $72(17 \%)$ & $30(17 \%)$ & 0.962 \\
\hline Mean SBP $(\mathrm{mmHg})$, mean (SD) $(N=587)$ & $150(19.6)$ & $147(18.0)$ & $155(22.2)$ & $<0.001$ \\
\hline $\mathrm{SBP}>160 \mathrm{mmHg}(N=587)$ & $168(29 \%)$ & $104(25 \%)$ & $64(37 \%)$ & 0.005 \\
\hline Mean DBP $(\mathrm{mmHg})$, mean $(\mathrm{SD})(N=587)$ & $82.2(10.5)$ & $82.0(10.3)$ & $82.8(10.9)$ & 0.351 \\
\hline $\mathrm{DBP}>90 \mathrm{mmHg}(N=587)$ & $120(20 \%)$ & $83(20 \%)$ & $37(21 \%)$ & 0.784 \\
\hline BMI (kg/m2), mean (SD) & $28.0(4.5)$ & $28.1(4.6)$ & $27.7(4.1)$ & 0.356 \\
\hline \multicolumn{5}{|l|}{ Antihypertensive medication } \\
\hline Diuretics & $308(52 \%)$ & $220(53 \%)$ & $88(50 \%)$ & 0.564 \\
\hline Angiotensin receptor blockers & $178(30 \%)$ & $137(33 \%)$ & $41(23 \%)$ & 0.021 \\
\hline Angiotensin II receptor antagonists & $229(39 \%)$ & $160(39 \%)$ & $69(39 \%)$ & 0.826 \\
\hline Beta-blockers & $197(33 \%)$ & $118(28 \%)$ & $79(45 \%)$ & $<0.001$ \\
\hline Calcium antagonists & $111(19 \%)$ & $66(16 \%)$ & $45(26 \%)$ & 0.005 \\
\hline
\end{tabular}

$T I A$ transient ischaemic attack, $B M I$ body mass index, GFR glomerular filtration rate, $S B P$ systolic blood pressure, $D B P$ diastolic blood

unselected elderly primary care patients with hypertension. Since hypertension is one of the most important risk factors for incident heart failure [3] and elderly hypertension patients represent a large proportion of patients in whom cardiovascular risk management is crucial, the results of this study are very relevant. By using echocardiography, we studied the association between symptoms and cardiac abnormalities and heart failure, including left ventricular dysfunction, diastolic dysfunction, LVH, and valvular dysfunction. A majority of research evaluated the association of symptoms and left ventricular systolic dysfunction only, and did not take other cardiac dysfunctions into account [8].

Some methodological issues need consideration. First, the cross-sectional design of the study does not allow for evaluation of the course of symptoms in relation to cardiac dysfunction. Second, the study population was primarily

Table 3 Sensitivity, specificity, positive predictive value, negative predictive value of symptoms associated with an abnormal echocardiogram $(N=175 / 591,30 \%)$

\begin{tabular}{lrllllllll}
\hline & $N(\%)$ & Sensitivity & $95 \% \mathrm{CI}$ & Specificity & $95 \% \mathrm{CI}$ & PPV & $95 \%$ CI & NPV & $95 \%$ CI \\
\hline Shortness of breath & $102(17 \%)$ & $32.3 \%$ & $14.3-20.6 \%$ & $71.0 \%$ & $66.6-74.9 \%$ & $29.6 \%$ & $26.0-33.5 \%$ & $70.4 \%$ & $66.5-74.0 \%$ \\
Fatigue & $110(19 \%)$ & $20.6 \%$ & $15.0-27.5 \%$ & $82.2 \%$ & $78.1-85.7 \%$ & $32.7 \%$ & $24.3-42.4 \%$ & $71.1 \%$ & $66.8-75.1 \%$ \\
Oedema of ankles, feet, legs & $78(13 \%)$ & $20.0 \%$ & $14.5-26.9 \%$ & $89.7 \%$ & $86.2-92.3 \%$ & $44.9 \%$ & $33.7-56.5 \%$ & $72.7 \%$ & $68.6-76.4 \%$ \\
Cold extremities & $137(23 \%)$ & $28.0 \%$ & $21.6-35.4 \%$ & $78.8 \%$ & $74.5-82.6 \%$ & $35.7 \%$ & $27.9-44.4 \%$ & $72.2 \%$ & $67.8-76.3 \%$ \\
Restless sleep & $149(25 \%)$ & $22.9 \%$ & $17.0-29.9 \%$ & $73.8 \%$ & $69.2-77.9 \%$ & $26.8 \%$ & $20.0-34.8 \%$ & $69.5 \%$ & $64.9-73.7 \%$ \\
\hline
\end{tabular}

$N P V$ negative predictive value, $P P V$ positive predictive value 
Table 4 Correlates of abnormal echocardiogram in elderly primary care hypertension patients (adjusted analysis; $N=587$ )

\begin{tabular}{|c|c|c|}
\hline & Odds ratio $(95 \% \mathrm{CI})$ & $P$-value \\
\hline \multicolumn{3}{|l|}{ Unadjusted analysis } \\
\hline \multicolumn{3}{|l|}{ Demographics } \\
\hline Female gender & $0.87(0.61-1.23)$ & 0.423 \\
\hline Age & $1.07(1.04-1.10)$ & $<0.001$ \\
\hline Having a partner & $0.60(0.41-0.89)$ & 0.012 \\
\hline \multicolumn{3}{|l|}{ Clinical history } \\
\hline Previous myocardial infarction & $3.71(1.68-8.16)$ & 0.001 \\
\hline Peripheral arterial disease & $2.26(0.98-5.22)$ & 0.057 \\
\hline $\mathrm{SBP}>160 \mathrm{mmHg}$ & $1.70(1.16-2.49)$ & 0.006 \\
\hline \multicolumn{3}{|l|}{ Symptoms } \\
\hline Shortness of breath & $1.17(0.74-1.85)$ & 0.505 \\
\hline Fatigue & $1.20(0.77-1.87)$ & 0.428 \\
\hline Oedema of lower extremities & $2.17(1.33-3.53)$ & 0.002 \\
\hline Cold extremities & $1.45(0.97-2.17)$ & 0.073 \\
\hline Restless sleep & $0.84(0.55-1.26)$ & 0.393 \\
\hline \multicolumn{3}{|l|}{ Adjusted analysis } \\
\hline \multicolumn{3}{|l|}{ Demographics } \\
\hline Female gender & $0.83(0.56-1.25)$ & 0.378 \\
\hline Age & $1.06(1.03-1.09)$ & $<0.001$ \\
\hline Having a partner & $0.71(0.46-1.11)$ & 0.135 \\
\hline \multicolumn{3}{|l|}{ Clinical history } \\
\hline Previous myocardial infarction & $3.00(1.28-7.03)$ & 0.011 \\
\hline Peripheral arterial disease & $1.44(0.70-4.37)$ & 0.230 \\
\hline $\mathrm{SBP}>160 \mathrm{mmHg}$ & $1.62(1.08-2.41)$ & 0.019 \\
\hline \multicolumn{3}{|l|}{ Symptoms } \\
\hline Shortness of breath & $0.90(0.53-1.53)$ & 0.702 \\
\hline Fatigue & $0.92(0.54-1.56)$ & 0.763 \\
\hline Oedema of lower extremities & $2.12(1.23-3.64)$ & 0.007 \\
\hline Cold extremities & $1.30(0.84-2.01)$ & 0.240 \\
\hline Restless sleep & $0.95(0.61-1.50)$ & 0.836 \\
\hline
\end{tabular}

$S B P$ systolic blood pressure, $D B P$ diastolic blood

Caucasian (99\%) limiting generalisability to other populations with more ethnic diversity. Another limitation is that we do not have detailed demographic information of the nonresponders. However, the response rate in the current study was almost $70 \%$. Moreover, the current design was not used to assess prevalence figures but rather to evaluate whether signs and symptoms could be associated with echocardiogram outcome.

\section{Comparison with existing literature}

Previous research showed that the most common symptoms associated with heart failure are oedema, dyspnoea, and fatigue $[14,15]$. However, most previous studies looking at the value of symptoms in the diagnosis of heart failure used selected samples of patients who were referred because of symptoms [25]. For example, patients in the study by Davie et al., in which the symptom oedema had no predictive value with low sensitivity and specificity, were referred for diagnosis of heart failure and the large majority were referred because of symptoms (dyspnoea) [19]. In another primary care study in patients with suspected heart failure similar findings were reported; oedema had limited value in the diagnosis of heart failure, and as in the current study no other symptoms were associated with heart failure diagnosis [17]. However, patients who visited for a specialised hypertension consultation were excluded, limiting the possibility to generalise the results to hypertension patients. Furthermore, in early stages of heart failure, milder symptoms do occur, which are generally insensitive in the diagnosis of heart failure [6]. Nevertheless, a diagnostic tool for heart failure in primary care was developed, based on a systematic review. According to this research, patients who present with symptoms of heart failure are most at risk when there is a history of MI, basal crepitations are present, and the patient is male with ankle oedema. The inclusion of oedema in this tool is more in line with our findings; however, this tool was developed for populations of patients with already suspected heart failure with presentation of symptoms [26], and therefore this tool is most likely not suitable for unselected elderly primary care patients with hypertension patients.

Although breathlessness is the most commonly reported symptom in established heart failure in primary care [16], our findings showed that oedema, and not shortness of breath, was significantly and independently associated with cardiac dysfunction as reflected by an abnormal echocardiogram, together with previous MI, higher age, and elevated systolic blood pressure. However, oedema had a low sensitivity making it less useful for ruling out cardiac dysfunction in elderly hypertension patients. The low sensitivity of all symptoms in our study can possibly be explained by the mild severity of cardiac dysfunction, with the majority of patients not reporting any symptoms.

Implications

In the majority of cases the GP is involved in the initial diagnosis of heart failure [16]. Therefore, attention to cardiac dysfunction predictive of chronic heart failure is important, especially in primary care populations at increased risk. The results of our study show that oedema of the lower limbs is significantly associated with cardiac dysfunction on an echocardiogram in elderly hypertension patients, it has modest positive predictive value, but adequate specificity. Although the value of symptoms is limited in the diagnosis of heart failure [17], oedema of the lower limbs could be of diagnostic value. The presence of oedema in elderly hypertension patients could alert the GP to initiate further assessment of cardiac function by means of echocardiography. To conclude, it would be recommended 
for GPs to check for oedema and consider an echocardiogram for further diagnosis of cardiac dysfunction, especially in elderly hypertension patients with a poorly controlled systolic blood pressure and/or a previous MI.

Ethical approval This study was approved by the medical ethics committee of the Elisabeth Hospital in Tilburg, the Netherlands.

Funding This work was supported by the non-profit primary care foundation Beloce.

Competing interests The authors declare that there are no conflicts of interest.

Open AccessThis article is distributed under the terms of the Creative Commons Attribution License which permits any use, distribution, and reproduction in any medium, provided the original author(s) and the source are credited.

\section{References}

1. Vasan RS, Beiser A, Seshadri S, et al. Residual lifetime risk for developing hypertension in middle-aged women and men: the Framingham Heart Study. JAMA. 2002;287:1003-10.

2. Aronow WS, Fleg JL, Pepine CJ, et al. ACCF/AHA 2011 expert consensus document on hypertension in the elderly: a report of the American College of Cardiology Foundation Task Force on Clinical Expert Consensus Documents. Circulation. 2011;123:2434-506.

3. Gottdiener JS, Arnold AM, Aurigemma GP, et al. Predictors of congestive heart failure in the elderly: the Cardiovascular Health Study. J Am Coll Cardiol. 2000;35:1628-37.

4. Bleumink GS, Knetsch AM, Sturkenboom MC, et al. Quantifying the heart failure epidemic: prevalence, incidence rate, lifetime risk and prognosis of heart failure. The Rotterdam Study. Eur Heart J. 2004;25:1614-9.

5. Hunt SA, Abraham WT, Chin MH, et al. 2009 Focused update incorporated into the ACC/AHA 2005 Guidelines for the Diagnosis and Management of Heart Failure in Adults A Report of the American College of Cardiology Foundation/American Heart Association Task Force on Practice Guidelines Developed in Collaboration With the International Society for Heart and Lung Transplantation. J Am Coll Cardiol. 2009;53:e1-90.

6. McMurray JJ, Adamopoulos S, Anker SD, et al. ESC Guidelines for the diagnosis and treatment of acute and chronic heart failure 2012: The Task Force for the Diagnosis and Treatment of Acute and Chronic Heart Failure 2012 of the European Society of Cardiology. Developed in collaboration with the Heart Failure Association (HFA) of the ESC. Eur Heart J. 2012;33:1787-847.

7. Schocken DD, Benjamin EJ, Fonarow GC, et al. Prevention of heart failure: a scientific statement from the American Heart Association Councils on Epidemiology and Prevention, Clinical Cardiology, Cardiovascular Nursing, and High Blood Pressure Research; Quality of Care and Outcomes Research Interdisciplinary Working Group; and Functional Genomics and Translational Biology Interdisciplinary Working Group. Circulation. 2008;117:2544-65.

8. Fonseca C. Diagnosis of heart failure in primary care. Heart Fail Rev. 2006;11:95-107.
9. Ewen E, Zhang Z, Kolm P, et al. The risk of cardiovascular events in primary care patients following an episode of severe hypertension. J Clin Hypertens (Greenwich). 2009;11:175-82.

10. Czernichow S, Zanchetti A, Turnbull F, et al. The effects of blood pressure reduction and of different blood pressurelowering regimens on major cardiovascular events according to baseline blood pressure: meta-analysis of randomized trials. $\mathrm{J}$ Hypertens. 2011;29:4-16.

11. Biskupiak JE, Kim J, Phatak H, et al. Prevalence of high-risk cardiovascular conditions and the status of hypertension management among hypertensive adults 65 years and older in the United States: analysis of a primary care electronic medical records database. J Clin Hypertens (Greenwich). 2010;12:935-44.

12. Calhoun DA, Jones D, Textor S, et al. Resistant hypertension: diagnosis, evaluation, and treatment. A scientific statement from the American Heart Association Professional Education Committee of the Council for High Blood Pressure Research. Hypertension. 2008;51:1403-19.

13. Llisterri JL, Rodriguez-Roca GC, Escobar C, et al. Treatment and blood pressure control in Spain during 2002-2010. J Hypertens. 2012;30:2425-31.

14. Bosworth HB, Steinhauser KE, Orr M, et al. Congestive heart failure patients' perceptions of quality of life: the integration of physical and psychosocial factors. Aging Mental Health. 2004;8:83-91.

15. Dahlstrom U, Hakansson J, Swedberg K, et al. Adequacy of diagnosis and treatment of chronic heart failure in primary health care in Sweden. Eur J Heart Fail. 2009;11:92-8.

16. Hobbs FD, Korewicki J, Cleland JG, et al. The diagnosis of heart failure in European primary care: the IMPROVEMENT Programme survey of perception and practice. Eur J Heart Fail. 2005;7:768-79.

17. Fonseca $\mathrm{C}$, Morais $\mathrm{H}$, Mota $\mathrm{T}$, et al. The diagnosis of heart failure in primary care: value of symptoms and signs. Eur J Heart Fail. 2004;6(795-800):21-2.

18. Knudsen CW, Riis JS, Finsen AV, et al. Diagnostic value of a rapid test for B-type natriuretic peptide in patients presenting with acute dyspnoe: effect of age and gender. Eur J Heart Fail. 2004;6:55-62.

19. Davie AP, Francis CM, Caruana L, et al. Assessing diagnosis in heart failure: which features are any use? QJM. 1997;90:335-9.

20. Chang SM, Hakeem A, Nagueh SF. Predicting clinically unrecognized coronary artery disease: use of two-dimensional echocardiography. Cardiovasc Ultrasound. 2009;7:10.

21. Davies M, Hobbs F, Davis R, et al. Prevalence of left-ventricular systolic dysfunction and heart failure in the Echocardiographic Heart of England Screening study: a population based study. Lancet. 2001;358:439-44.

22. Leung DY, Chi C, Allman C, et al. Prognostic implications of left atrial volume index in patients in sinus rhythm. Am J Cardiol. 2010;105:1635-9.

23. Lang RM, Bierig M, Devereux RB, et al. Recommendations for chamber quantification. Eur J Echocardiogr. 2006;7:79108.

24. Nagueh SF, Appleton CP, Gillebert TC, et al. Recommendations for the evaluation of left ventricular diastolic function by echocardiography. J Am Soc Echocardiogr. 2009;22:107-33.

25. Mant J, Doust J, Roalfe A, et al. Systematic review and individual patient data meta-analysis of diagnosis of heart failure, with modelling of implications of different diagnostic strategies in primary care. Health Technol Assess. 2009;13:1-207.

26. Roalfe AK, Mant J, Doust JA, et al. Development and initial validation of a simple clinical decision tool to predict the presence of heart failure in primary care: the MICE (Male, Infarction, Crepitations, Edema) rule. Eur J Heart Fail. 2012;14: $1000-8$. 